\title{
Communication in Healthcare: Global challenges in the 21st Century
}

\author{
Harriet Rosanne Etheredge $\mathrm{e}^{1,2}$ June Fabian ${ }^{1,3}$ \\ ${ }^{1}$ Wits Donald Gordon Medical Centre, School of Clinical Medicine, \\ Faculty of Health Sciences, University of the Witwatersrand, \\ Johannesburg, South Africa \\ ${ }^{2}$ Steve Biko Centre for Bioethics, School of Clinical Medicine, Faculty \\ of Health Sciences, University of the Witwatersrand, Johannesburg, \\ South Africa \\ 3 Department of Internal Medicine, School of Clinical Medicine, \\ Faculty of Health Sciences, University of the Witwatersrand, \\ Johannesburg, South Africa
}

Hamostaseologie 2022;42:29-35.

\author{
Address for correspondence Harriet Etheredge, PhD, Max Price \\ Building, Wits Donald Gordon Medical Centre, 27 Eton Road, \\ Parktown, Johannesburg, 2193, South Africa \\ (e-mail: harriet.etheredge@mediclinic.co.za).
}

\begin{abstract}
Keywords

- social media

- health communication

- digital platforms

- ethics

- law

This article explores the communication challenges brought about by the digital revolution in the 21 st century for healthcare professionals internationally. It particularly focuses on the use of content-generating and sharing platforms like social media. Globally, healthcare has been irrevocably altered by digital innovation and health professionals deploy an extensive range of social media and web-based tools on a daily basis. However, many healthcare professionals use these platforms in a regulatory vacuum-where there may not be specific legal or ethical guidance-and without an appreciation of the associated risks. Given the special protections afforded to the practitioner-patient relationship, and the importance of a health practitioners' reputation, it is vital that we understand how to traverse the many ethical and legal challenges of the digital interaction. A comprehensive set of recommendations (see "Guidelines for Good Digital Citizenship in the Health Professions" on page $5 \mathrm{ff}$.) to keep practitioners out of trouble is provided. These hinge on the notion of being a "good person and a good doctor" as a formative maxim for ethical and legal safety. The constituents of publication, and the consequences of falling foul of acceptable publication standards on social media, are specifically discussed. "Publication" involves sharing content with a third party, or a group of people, and social media refers to platforms on which content can be shared with more than one person. Hence, most information that we post on social media can be considered as "published," and as such may attach liability for health professionals who do not use these platforms with requisite care and sufficient forethought.
\end{abstract}

\section{Introduction}

Twenty-first century life is lived in two separate, but critically interlinked, worlds. One is the physical, tangible world -ourselves and our families, our friends, our possessions, and sometimes our hobbies and passions. The other is the digital world-the elusive, omnipresent World Wide Web composed of trillions of terabytes of data we cannot see, feel, or imagine, yet a space where many of us spend more time and energy than we do in the physical world. Our dependence on digital platforms is evidenced by the way we have invited such into our daily lives. Most of us have received

August 30, 2021

accepted after revision

November 4, 2021 (c) 2022. Thieme. All rights reserved. Georg Thieme Verlag KG,

Rüdigerstraße 14,

70469 Stuttgart, Germany
DOI https://doi.org/ 10.1055/a-1685-7096. ISSN 0720-9355. 
smartphones, which are an open door into the digital world. Many people check their social media channels first thing in the morning-before reaching out to those who may be physically present with them and extending a greeting. The apps we have on our digital devices, and the design of those devices themselves, are so utterly intuitive that even very young children can easily access them, sometimes with devastating effect. ${ }^{1,2}$

But it is not only our personal lives that have been irrevocably altered by digital innovation, industry too has fundamentally changed. There are few professions that have not been swept up in the myriad new technologies available. Healthcare is no exception. Today, aside from the use of social media in their personal lives, healthcare professionals (HCPs) deploy digital platforms when providing care to patients. ${ }^{3,4}$ Additionally, the COVID-19 pandemic may have thrust healthcare into the digital domain faster than anticipatedgiving many HCPs no choice but to embrace digital technology to continue practicing. For instance, telemedicine has become a cornerstone of patient consultation, and video streaming services have been installed by health institutions and HCPs to facilitate connection with loved ones isolated in hospital.

The huge power conferred on us by digital technology comes with commensurate responsibility, and a different set of "rules of engagement" which, for a HCP, adds an extra layer of complexity in terms of ethically sound and legally acceptable best practice. The rules governing digital interactions by HCPs in our professional lives are inevitably different from those that guide our personal lives-we have an obligation to familiarize ourselves with these rules, and we need to be aware that they are not mutually exclusive.

This article explores the communication challenges that the digital revolution has created for HCPs in the 21st century. We argue that because of special protections afforded to the HCP-patient relationship, and the importance of a HCP's reputation, it is vital that we understand how to traverse the many ethical and legal challenges of the digital world. In particular, an appreciation for the intricacies of "publication" can serve us well. Our argument is framed with acknowledgment that these technologies have huge healthcare benefits-and their power should be harnessed. We also advance some recommendations to stay out of trouble when navigating the complex intersection between the physical and digital domains, and our personal and professional use of these platforms. Our recommendations hinge on the notion of being a "good person and a good doctor" as a positive maxim for safe use of digital platforms. It is beyond the scope of this article to address the roles of institutions in regulating the digital interactions of their employees, apart from referring individuals to their relevant institutional policies. Similarly, the reputational risks that may accrue to healthcare students as the result of irresponsible digital citizenship are for another article, but it is important for students to remember that unlike verbal communication, which is almost always ephemeral, digital content should be regarded as permanent. Even the most dogged efforts to eliminate it may fail.

\section{Definitions}

Healthcare professional (HCP) refers to any individual delivering healthcare in the biomedical domain and registered with the associated professional society or government department. It includes (but may not be limited to) medical doctors, nurses, allied health professionals, dentists, and clinical associates.

Social media "describes the online tools and electronic platforms that people use to share content such as opinions, information, photos, videos, and audio. [It] includes social networks (e.g. Facebook (Meta), Twitter, WhatsApp, and LinkedIn), content-sharing platforms (e.g. YouTube, Instagram, Zoom, Teams, SignApps, Logbox, TikTok, and Snapchat), personal and professional blogs (including email, SMS, electronic journals, as well as those published anonymously), internet discussion forums, and the comment sections of websites." ${ }^{5-8}$

Social media channels refer to the actual social media that any given individual might use. For instance, one person may use Facebook (Meta), Twitter, and Instagram to publish content. Another may use Facebook (Meta), WhatsApp, and TikTok to do the same.

Digital platforms include all social media-as previously defined-as well as other software such as electronic patient record systems, hospital booking systems, diagnostic apps, robot-assisted surgical devices, artificial intelligence diagnostic algorithms, medical cloud storage systems, and service delivery algorithms.

\section{Digital Communications in Healthcare}

The application of technology in health communication broadly covers HCP use of digital platforms to communicate about patients and their utilization to communicate with patients-this is a particularly gray area as it has been argued that interaction with patients on social media, in particular, can leave a HCP vulnerable to other ethical dilemmas. ${ }^{5}$

The utility of digital platforms in the healthcare setting is undisputable. Content-sharing services have enhanced communication with patients and between healthcare teams, as well as facilitating specialist referral or input for complicated cases. The fact that many of these services claim superior end-to-end encryption may engender reticence about their potential to offer a safe space for such communication. Electronic record keeping has streamlined healthcare, and these data can be easily exported, downloaded, and analyzed for audit purposes and professional credentialing. Moreover, the efficiency of social media to connect rural HCPs with medical specialists has been widely documented, ${ }^{9,10}$ as has the utility of computerized linkage to care for managing communicable diseases like tuberculosis ${ }^{11}$ and more recently test and trace systems for COVID-19. ${ }^{12}$ Many HCPs utilize social media to share medical information, and these platforms are sometimes used for teaching and learning.

Overall, it seems widely accepted that digital platforms have improved clinical communication, facilitating continuity and standardization of care, as well as enhancing 
transparency and accessibility. ${ }^{13}$ However, it has also been noted that many HCPs are not aware of the legal and ethical pitfalls of social media use, and do not appreciate the potential to get into trouble when using digital platforms. ${ }^{14}$ This is where the HCP-patient relationship and the complementary notion of public trust in the health system play a vital role.

\section{Digital Platforms and the HCP-Patient Relationship}

Effective healthcare hinges on the relationship of trust between practitioner and patient. ${ }^{15}$ The consequence of lacking public trust in the health system is that people will be increasingly unwilling to approach providers for care, and as such the overall health of the population will suffer. ${ }^{16}$ Hence, promoting and protecting the "fiduciary relationship" between HCP and patient is the cornerstone of much medical legislation, its attendant regulations, and ethical guidelines. ${ }^{17}$ There are few other professions that protect the relationship between parties so vociferously, perhaps the closest being law. As such, there is an additional burden on HCPs to be especially cautious in all their dealings with the public.

The fiduciary relationship can be eroded in many ways. These include (but are not limited to) breaches of confidentiality, failure to obtain informed consent, medical negligence or malpractice, ineffective communication, perceived systemic challenges related to healthcare delivery, and the eventual portrayal of these issues in the media. ${ }^{18}$ With the acceleration in digital platform use for healthcare, new threats to the HCP-patient relationship and the trust it is attendant upon have emerged. ${ }^{19,20}$ These include an extension of traditional barriers to the fiduciary relationship-but also the threat of being hacked, recorded (covertly or overtly), the theft of devices on which confidential information is stored, and unauthorized access to these devices. The digital world gives HCPs increasing opportunities to make mistakes -such as sharing confidential patient information with the wrong social media group, or being video recorded behaving inappropriately and having the recording posted on a social media channel for the world to see. This makes threats to the fiduciary relationship all the more public, and it speaks to why HCPs should carefully guard not only their in-person but also their online reputations.

\section{Ethics, the Law and Publication}

From a programming and development perspective, digital platforms evolve incredibly fast. This evolution has far outpaced legislators, legal systems (where cases are heard), and the main international bodies responsible for ethical regulation of healthcare. As a result, many HCPs utilize social media in a regulatory vacuum-where there may not be specific legal or ethical guidance related to digital platforms in healthcare as a specific entity. HCPs may not be protected by the institution in which they work, and perhaps not by their professional malpractice insurance; and HCPs should investigate this in their specific jurisdictions. However, we can draw on international ethical and legal principles of healthcare practice, as well as concepts inherent to slander, libel, and defamation (among others), to extrapolate some ground rules for digital platforms and use of social media by HCPs.

\section{Content Sharing}

The definition of social media used in this article (see "Definitions" section) is derived from several international guidelines for HCPs. The convergence in these sources is the positioning of social media as any platform that facilitates the two-way sharing of content. This includes messaging services, SMS and email. However, to appreciate why medical communication on social media can get one into trouble requires not only an understanding of what social media is, but also an understanding of exactly what we are doing when we post onto social media. The thin end of the wedge involves posting something that is illegal, inappropriate, or harmful. This could result in criminal or civil charges against HCPs, or professional censure, suspension, and revocation of license to practice. For instance, the College of Physicians and Surgeons of Ontario has issued extensive guidelines for physician social media use, and these have been cited in reprimanding physicians who have made hateful comments, or spread misinformation related to COVID-19. ${ }^{21}$

To establish how this is so, the definition of publication as it applies internationally to libel (written statements), slander (verbal statements), ${ }^{22}$ and defamation is illuminating. The strict legal interpretation, implementation, and evidentiary obligations to prove these charges differ from country to country. However, a relative commonality is that once any content has been seen (and in some jurisdictions explicitly understood $)^{23}$ by a third party in addition to the original subject of the content, the reputation of the subject can suffer damages because the content is considered to be published. $^{22,24,25}$

Two concepts merge in the definitions utilized here that are imperative for our argument. First, "publication" involves sharing content with a third party, or a group of people. Second, social media refers to platforms on which content can be shared with more than one person. Hence, nearly all information that we post on social media can be considered as "published," and as such may attach the same, if not more, legal liability as falls to a journalist publishing an article or running a story on a news platform. In the majority, these journalists and the companies publishing their stories exercise intensive due diligence to ensure that what they are sharing is factually correct and cannot get them into legal trouble. The difference with digital publications and social media posts is that they are instantaneous, and seldom enjoy the same level of prepublication scrutiny.

However, the legal repercussions when a layperson posts damaging or inappropriate content can be more severe than when censuring journalists. The difference between a layperson and a journalist is thanks to legal doctrine like stare decisis ${ }^{26}$ and the precedent setting cases such as New York Times Co. v. Sullivan, 376 U.S. 254 that it upholds. ${ }^{27}$ 
Journalists are protected by the right to freedom of the press and this makes it more difficult for a public figure to sue a journalist for libel or slander than it would be to sue a regular person for the same. These protections of press freedom facilitate publication of issues firmly in the public interest, such as reporting on the Watergate Scandal, and do not extend to the average person publishing harmful content on their social media channels.

\section{Chain of Publication}

To make this scenario more complex, the "chain of publication" is another important legal concept we need to be aware of. In short, the chain of publication notes that anyone who associates with a defamatory, libelous, or slanderous statement by repeating it, confirming it or interacting with it, is, in principle, as liable for that content as the person who originally published it. ${ }^{23,24,28}$ An example from the healthcare context illustrates this point: Dr. J. publishes a teaching and learning post that identifies a patient on social media. Dr. J. has not obtained consent from the patient to make this post. Dr. H. sees the post, likes it, and shares it on their own social media channels. According to the chain of publication, by sharing the content, Dr. H. is as responsible for the breach of confidentiality and lack of informed consent as Dr. J. is. Moreover, posts to groups hosted on social media platforms that may seem private-because of end-to-end encryption or two-factor authentication-are considered published, because they are seen (and understood) by more than one other person. ${ }^{14}$ As such, these groups should not be considered a "safe space."

Individuals can take certain actions to remove themselves from the chain of publication. For instance, in some jurisdictions, disassociating oneself from inappropriate content posted on a social media group to which they are party would suffice, or leaving social media groups and channels where inappropriate content is circulated. ${ }^{14}$ The defense of "innocent dissemination" stands in some cases where people do not fully appreciate the nature of the content they have shared. ${ }^{28}$ However, as HCPs, the implications of becoming involved in the chain of publication should give us real pause for thought when we interact with content by sharing, liking, or commenting on it.

\section{“Private" Messages between Only Two People}

According to our definitions, private messages between only two individuals would not be considered published, and given safeguards like end-to-end encryption and two-factor authentication, it is easy to assume that these communications are inaccessible to third parties. ${ }^{14,29}$ However, this is a "screengrab" world. If one person sends something inappropriate to another person, there is little to prevent that receiving party from taking a screenshot of the inappropriate content and sharing it if needs be. Reasons to share such content would be if it were in the public interest, to hold the original author to account, to report illegal activity, or to protect the original recipient of the content in an unpleasant situation. The dissemination of this information would constitute its publication. For this reason, acting as though private conversations are not "published" and are thus somehow exempt is a dangerous assumption that could have serious consequences.

\section{Digital Platforms Sanctioned by One's Hospital or Practice}

Digital platforms designed for the specific purpose of sharing or recording clinical information have proliferated internationally. These platforms often boast data safeguards commensurate to the value of patient information and acknowledge the risk that a breach of patient information poses. Many healthcare organizations have invested in a preferred provider of these services, often at substantial cost. Access to these services by more than one person is implied; so, inputting information would still constitute publication even with an institutional sanction, and HCPs should be mindful of this when recording notes about patients or colleagues. However, HCPs may be contractually obliged to utilize such systems. Medical record keeping is essential and obligatory, ${ }^{30}$ and the sharing of patient information under specific conditions is not a breach of confidentiality. ${ }^{31}$ Moreover, when a platform is sanctioned by an institution it may undertake-within reason-to support an employee who breaches legal or ethical rules when using the platform. This is not guaranteed and should not be seen as inviting reckless or inappropriate use of this technology.

\section{Reputation Management, Career Progression, and the Use of Social Media for HCPs}

Given that:

- Most information we post on digital platforms and social media is considered published, and can be easily disseminated to third parties and,

- The associated chain of publication when we interact with published statements

It follows that HCPs need to be particularly judicious when utilizing these digital platforms.

Reputation is a fundamental determinate of a successful career in healthcare. ${ }^{32}$ For instance, being reputed as a "good doctor" facilitates word-of-mouth recommendations, positive reviews, promotion, and recognition, with resultant career advancement and larger patient throughput. Alternatively, a HCP of poor repute may not advance satisfactorily, because patients want someone who can be relied upon to deliver them the best possible health service. ${ }^{32}$

Notably, HCPs are at risk of bad repute regardless of their clinical acumen, because in some instances the "court of public opinion" holds greater sway than diligent establishment of the facts. Reputational damage is particularly implicated in the trend of "HCP rating" by patients (in much the same way one would rate a restaurant). ${ }^{33,34}$ Negative posts about HCPs-authored by patients-can gain traction or go viral on social media. The voracity of these posts is almost irrelevant in the court of public opinion, and they have the capacity to rapidly engage a huge number of people who may jump to judgment without all the facts. Reputational damage 
can result, and shape general perception, long before a serious matter is adjudicated in a court of law (or arbitration forum, etc.). Rewinding such damage is a monumental and lengthy task, and for HCPs, a guilty verdict in the court of public opinion could do irrevocable reputational harm.

HCPs should also be aware of damaging their own reputation-or that of their institution-through their actions on social media. This can occur if a HCP posts inappropriate content in their personal capacity, but also if the post by an HCP constitutes a breach of confidentiality or informed consent, identifies a patient, or brings their institution or profession into disrepute (among other examples). In these instances, remembering the basic rules of publication is essential. If one shares patient information on a WhatsApp group, for instance, that includes individuals who are not part of the treating team and as such do not have a right to such information, we may have inadvertently published confidential information, which may have ethical and legal consequences.

The foregoing analysis begs the question: How should HCPs conduct themselves in their personal and professional lives, while upholding ethical and legal best practice?

\section{Good Person-Good Doctor}

The final section of this article provides a set of guidelines for responsible and safe use of digital platforms as HCPs.

There is an overarching moral rule, however, that may apply universally to personal and professional conduct-both in person and online. Living by this rule already goes a long way toward keeping HCPs out of trouble and preserving reputation. Though it may sound banal, the rule is to strive to be a good person, and a good professional. The former implies living our lives in a way that will not harm others, and practicing the "Golden Rule," enshrined in the writings of Immanuel Kant as the Categorical Imperative. ${ }^{35}$ This involves always treating others as ends in themselves, not as a means to an end and behaving as though the maxim of one's action would become a universal law. This is often interpreted as treating others in the manner you would wish to be treated. In the digital world, this equates to dealing responsibly with content and being a good digital citizen. ${ }^{29}$ Being a good HCP involves practicing to the ethical and legal standards expected of us, trying to embody the spirit of the Hippocratic Oath in practice and remembering that the core of clinical practice is compassion in all our dealings.

\section{Guidelines for Good Digital Citizenship in the Health Professions}

\section{At Work}

- Workplace social media policies are often designed to protect the reputation of the institution, and it is important to be familiar with these. ${ }^{36}$ As such, there will often be repercussions for individuals who post harmful content that, by association with that individual, brings their institution into disrepute. While one may not make explicit reference to their institution on social media channels, a simple Google search can link employees or associates to an organization. Consequently, posts made in one's "personal capacity" can still result in ethical or legal trouble. Having a "disclaimer" in a personal social media bio stating that an HCP's views are not those of their institution, while often required by institutions themselves, may not exonerate the publication of harmful content. ${ }^{37}$

- Beware of utilizing digital platforms and posting on social media when feeling stressed, exhausted, burned out, and emotionally fatigued-all common sensations for HCPs. Practice techniques like "sleeping on it" and only posting the content when one has a clear head. The Phone Breakup (https://phonebreakup.com/lockscreendownloads) assists impulsive posters by providing a customizable lock screen image that you can download. It will prompt you to "think twice" before accessing your phone.

- Undertake regular digital reputation audits by frequently searching for yourself (use a range of search engines and devices as each will display different results). Given the extreme difficulty of getting negative content removed from the Internet, it is important to have a transparent and actionable complaints and compliments policy within a practice. This can mitigate patients taking their grievances public, by positing about an HCP online. Platforms that host HCP reviews will only remove content under exceptional circumstances as they cannot be seen to violate free speech, ${ }^{38}$ so a statement that one was late, rude, slow, etc. is very unlikely to be deleted. Although illegal statements will be removed, legal processes may precede this and become a costly undertaking. Whether an HCP's malpractice insurance would cover this depends on the specific insurer, so cannot be taken for granted. If HCPs find negative reviews of themselves online, some research $^{39}$ has shown that neutrally engaging with these in a manner that does not violate data protection legislation or breach confidentiality will be viewed more positively by others reading the reviews than will reviews where there has not been a response. A sentence like "Thank you for the review, the practice will make contact with you to discuss your concerns" is a good first step, though you would then need the resources and willpower to follow-through.

- To avoid the reputational damage that may arise if a patient posts negative comments about a HCP on social media, acting as though one is always being recorded in a consult with a patient, and that this recording may find its way onto social media, is a sensible precaution.

- In many countries, it is illegal to post the trade names or prices of scheduled medicines, or medical devices, on social media or any other type of publication. ${ }^{40}$ Furthermore, any post that may be viewed as coercive or enticing a patient to access the services of one practitioner over another-by offering discounts or making statements about the superior skill of the $\mathrm{HCP}$-may be unethical and could result in legal trouble. ${ }^{41,42}$ Hence, HCPs who use social media for advertising or marketing should be familiar with the legal and ethical guidelines in their region. 


\section{When Sharing Patient Information}

- Avoid sharing patient information on any digital platform unless it is essential for patient management and record keeping. When using clinical platforms beyond the ambit of patient management and with a wider clinical team, such as multidisciplinary team groups, never assume that the person who originally generated content related to a patient had consent from that patient to post it onto social media. Avoid sharing content if uncertain of its voracity, ethical merit, and legal underpinnings.

- When curating social media channels related to work in healthcare, always get consent from patients to post any of their information. International data protection trends oblige publishing the absolute minimum amount of information necessary to achieve one's ends, and also require that content is anonymized as far as possible. ${ }^{43}$

\section{In Life}

- Remember that messages into social media groups are seen by more than one other person and would hence be considered published. So, be very vigilant about posts into groups. Always stick to the topic at hand, and be friendly and neutral.

- If friends or family members tag or mention HCPs in inappropriate content that could cause reputational harm (even on your personal social media channels only), ask them to remove the tags or un-tag yourself. The same applies for comments or posts HCPs are mentioned in, which then appear on the newsfeeds of your social media platforms. Being tagged in such a way may render one part of the chain of publication, and it is important to take measures to distance yourself from content which is inappropriate or could harm your reputation as an HCP.

- Posting fake news on social media is illegal in many jurisdictions. ${ }^{44}$ If sharing fake news for the purposes of warning the public that it is such, do not magnify the harm already done by the news (so share a screenshot of a fake news video clip rather than the clip in its entirety). Also, clearly caption shares with the fact that they are fake news, and that you do not endorse or in any way agree with its content.

We have endeavored to make this guidance as comprehensive as possible; however, it is not an exhaustive list and it should always be read alongside the relevant legislation in the country and jurisdiction under which one is registered to practice. Importantly, these guidelines do not constitute legal advice.

\section{Conflict of Interest}

The authors declare that they have no conflict of interest.

\section{References}

1 Baek HW, Shin YM, Shin KM. Emotional and behavioral problems related to smartphone overuse in elementary school children. JKNA 2014;53(05):320-326
2 Sohn S, Rees P, Wildridge B, Kalk NJ, Carter B. Prevalence of problematic smartphone usage and associated mental health outcomes amongst children and young people: a systematic review, meta-analysis and GRADE of the evidence. BMC Psychiatry 2019;19(01):1-10

3 West DM, Miller EA. Digital Medicine: Health Care in the Internet Era. Washington, DC: Brookings Institution Press; 2009

4 Torous J, Michalak EE, O'Brien HL. Digital health and engagement -looking behind the measures and methods. JAMA Netw Open 2020;3(07):e2010918-e2010918

5 Health Professions Council of South Africa. Ethical guidelines on social media - Booklet 16. 2019 Accessed August 13, 2021 at: https://www.hpcsa.co.za/Uploads/Professional_-

Practice/Conduct\%20\%26\%20Ethics/Ethical2\%20Guidelines\% 20on\%20Social\%20Media.pdf

6 European Commission. 13 Social Media. 2021 Accessed August 30 , 2021 at: https://wikis.ec.europa.eu/display/WEBGUIDE/01.+ Using+social+media

7 European Union. Proposal for a regulation of the European Parliament and of the Council on a Single Market For Digital Services (Digital Services Act) and amending Directive 2000/31/ EC. 2020 Accessed August 30, 2021 at: https://eur-lex.europa.$\mathrm{eu} /$ legal-content/EN/TXT/PDF/? uri=CELEX:52020PC0825\&from $=$ en

8 National Health Service England and Wales. Social media and attributed digital content policy. 2017 Accessed August 30, 2021 at: https://www.england.nhs.uk/wp-content/uploads/2018/04/ social-media-policy.pdf

9 Venter W, Coleman J, Chan VL, et al. Improving linkage to HIV care through mobile phone apps: randomized controlled trial. JMIR Mhealth Uhealth 2018;6(07):e155

10 Venter WDF, Fischer A, Lalla-Edward ST, et al. Improving linkage to and retention in care in newly diagnosed HIV-Positive patients using smartphones in South Africa: Randomized controlled trial. JMIR Mhealth Uhealth 2019;7(04):e12652

11 Mgode G, Bwana D, Cox C, Batra S, Richter C, Fiebig L. Monitoring Tuberculosis (TB) treatment adherence using eCompliance digital tool by community healthcare workers. In: Digital Literacy and Socio-Cultural Acceptance of ICT in Developing Countries (231241). Springer International; 2021 Online. Accessed August 30, 2021 at: https://www.springerprofessional.de/en/monitoringtuberculosis-tb-treatment-adherence-using-ecompliance/ 19213930

12 Chidambaram S, Erridge S, Kinross J, Purkayastha SPanSurg Collaborative. Observational study of UK mobile health apps for COVID-19. Lancet Digit Health 2020;2(08):e388-e390

13 Khayamian Esfahani B, Bause M, Schaefer D. Health 4.0: How digitisation drives innovation in the healthcare sector. The 2019 International Conference on Systematic Innovation. Liverpool, UK; 08-11 July. Accessed August 30, 2021 at: https://repository. uel.ac.uk/item/87w36

14 Bouter C, Venter B, Etheredge H. Guidelines for the use of WhatsApp groups in clinical settings in South Africa. S Afr Med J 2020; 110(05):364-368

15 Chandra S, Mohammadnezhad M, Ward P. Trust and communication in a doctor-patient relationship: a literature review. J Healthc Commun 2018;3:36

16 Hawley K. Trust and distrust between patient and doctor. J Eval Clin Pract 2015;21(05):798-801

17 Hill CA, McDonnell BH. Fiduciary duties: the emerging jurisprudence. In: Research Handbook on the Economics of Corporate Law. Edward Elgar Publishing; 2012

18 Etheredge HR, Penn C, Watermeyer J. A qualitative analysis of South African health professionals' discussion on distrust and unwillingness to refer organ donors. Prog Transplant 2018;28 (02):163-169

19 Grobler C, Dhai A. Social media in the healthcare context: ethical challenges and recommendations. SAJBL 2016;9(01):22-25 
20 Terrasse M, Gorin M, Sisti D. Social media, e-health, and medical ethics. Hastings Cent Rep 2019;49(01):24-33

21 College of Physicians and Surgeons of Ontario. Social MediaAppropriate Use by Physicians. 2020 Accessed October 22, 2021 at: https://www.cpso.on.ca/Physicians/Policies-Guidance/Statements-Positions/Social-Media-Appropriate-Use-by-Physicians

22 Shouse Injury Law Group. California Defamation (Libel and Slander) Laws. Accessed August 30, 2021 at: https://www.shouselaw. com/ca/personal-injury/harm-to-reputation/defamation/

23 LexisNexis. Defamation and malicious falsehood-Publication. Accessed August 30, 2021 at: https://www.lexisnexis.co.uk/legal/guidance/defamation-malicious-falsehood-publication

24 SraussDaly. Freedom of Speech and the law of Defamation. Accessed August 30, 2021 at: https://www.straussdaly.co.za/freedom-of-speech-and-the-law-of-defamation/

25 Health and Safety Executive - UK Government. Defamation: Libel and slander. Accessed August 30, 2021 at: https://www.hse. gov.uk/enforce/enforcementguide/court/reporting-defamation. htm\#P15_1719

26 Kozel RJ. Statutory Interpretation, Administrative Difference and the Law of Stare Decisis. Texas Law Review 1125 (2019), Notre Dame Legal Studies Paper No. 1859. Accessed October 22, 2021 at: https://ssrn.com/abstract=3312818

27 Barbas S. The Press and Libel before New York Times v. Sullivan. Colum JL \& Arts. 2020;44:511 Doi: 10.52214/jla.v44i4.8195

28 Dobson H. Facebook Hosts and Third Party Posts: Defamation in the Internet Age. University of OtagoNew Zealand2015 Accessed August 30, 2021 at: https://www.otago.ac.nz/law/otago451213. pdf

29 Harrison L, Sadlier E. Selfies, Sexts and Smartphones: A Teenager's Online Survival Guide. South Africa: Penguin Random House; 2017

30 Medical Protection Society UK. An essential guide to medical records - Advice for the United Kingdom. 2017 Accessed August 30, 2021 at: https://mpscdnuks.azureedge.net/resources/docs/mp/advice-booklets/medicolegal-guides/advice-bookletguide-to-medical-records.pdf

31 Health Professions Council of South Africa. Confidentiality: Protecting and providing information. Accessed August 30, 2021 at: https://www.hpcsa.co.za/Uploads/Professional_Practice/Conduct $\% 20 \% 26 \% 20$ Ethics/Booklet\%205\%20Confidentiality\%20Protecting\%20and\%20Providing\%20Information\%20September\% 202016.pdf

32 Jabeen F, Hamid Z, Akhunzada A, Abdul W, Ghouzali S. Trust and reputation management in healthcare systems: taxonomy, requirements and open issues. IEEE Access 2018;6:17246-17263
33 Rothenfluh F, Schulz PJ. Physician rating websites: What aspects are important to identify a good doctor, and are patients capable of assessing them? A mixed-methods approach including physicians' and health care consumers' perspectives. J Med Internet Res 2017;19(05):e127

34 Lagu T, Metayer K, Moran M, et al. Website characteristics and physician reviews on commercial physician-rating websites. JAMA 2017;317(07):766-768

35 Myskja BK. The categorical imperative and the ethics of trust. Ethics Inf Technol 2008;10(04):213-220

36 Eldor K. 2018Why every company needs a workplace social media policy. Accessed August 30, 2021 at: https://hiring.monster.ca/employer-resources/workforce-management/improvingemployee-relations/workplace-social-media-policy/

37 Van Hove F, Asdourian B, Bourgeois D. My tweets are (not) my own! "Normalizing" journalists' branding and digital identity on Twitter. Pop Commun 2018;16(04):263-275

38 Taffet GE. Hospital and physician rating websites: Ethical challenges without context. Ethical Considerations and Challenges in Geriatrics 137-145. Springer - Online. 2017. Accessed August 30, 2021 at: https://link.springer.com/chapter/10.1007/978-3-31944084-2_12

39 Vafeiadis M. Message interactivity and source credibility in online dental practice reviews: responding to reviews triggers positive consumer reactions regardless of review valence. Health Commun $2021 ; \cdots \cdots: 1-11$

40 Donohue J. A history of drug advertising: the evolving roles of consumers and consumer protection. Milbank Q 2006;84(04): 659-699

41 Joa CY, Park S-Y. Entrepreneurial doctors and consumerist patients: \#plasticsurgery on Instagram. Int J Pharm Healthc Mark 2021 (epub ahead of print). Doi: 10.1108/IJPHM-01-20200002

42 Health Professions Council of South Africa. Guidelines for good practice in the Health Care Professions. 2016. Accessed August 30 , 2021 at: https://www.hpcsa.co.za/Uploads/Professional_Practice/Conduct $\% 20 \% 26 \% 20$ Ethics/Booklet\%202\%20Generic\%20Ethical\%20Rules\%20with\%20anexures\%20September\%202016.pdf

43 Buys M. Protecting personal information: Implications of the Protection of Personal Information (POPI) Act for healthcare professionals. S Afr Med J 2017;107(11):954-956

44 Haciyakupoglu G, Hui JY, Suguna V, Leong D, Rahman MFBA. Countering fake news: a survey of recent global initiatives. ThinkASIA Policy Report. 2018. Accessed August 30, 2021 at: https://www.think-asia.org/handle/11540/8063 